\title{
A Surgical Method for Determining Proper Screw Length in ACDF
}

\author{
Hae-Gi Park, Moo-Sung Kang, Kyung-Hyun Kim, \\ Jeong-Yoon Park, Keun-Su Kim, Sung-Uk Kuh \\ Department of Neurosurgery, Spine and Spinal Cord Institute, Yonsei University College of Medicine, Seoul, Korea
}

Objective: We describe a surgical tool that uses the distractor pin as a reference for determining proper screw length in ACDF. It is critical that screw purchase depth be as deep as possible without violating or penetrating the posterior cortical wall, which ensures strong pull out strength.

Methods: We enrolled 81 adult patients who underwent ACDF using an anterior cervical plate from 2010 to 2012. Patients were categorized into Groups A (42 patients: retractor pin used as a reference for screw length) and B (39 patients: control group). Intraoperative lateral $\mathrm{x}$-rays were taken after screwing the retractor pin to confirm the approaching vertebral level. The ratio of retractor pin length to body anteroposterior (A-P) diameter was measured as a reference. Proper screw length was determined by comparison to the reference.

Results: The average distance from screw tip to posterior wall was $3.0 \pm 1.4 \mathrm{~mm}$ in Group A and $4.1 \pm 2.3 \mathrm{~mm}$ in Group B. The ratio of screw length to body sagittal diameter was $86.2 \pm 5.7 \%$ in Group A and $80.8 \pm 9.0 \%$ in Group B. Screw length to body sagittal diameter ratios higher than $4 / 5$ occurred in 33 patients (90\%) in Group A and 23 patients (59\%) in Group B. No cases violated the posterior cortical wall.

Conclusion: We introduce a useful surgical method for determining proper screw length in ACDF using the ratio of retractor pin length to body A-P diameter as a reference. This method allows for deeper screw purchase depth without violation of the posterior cortical wall.

Key Words: Anterior cervical discectomy and fusion $(A C D F) \cdot S c r e w$ pullout strength $\cdot$ Screw length

\section{INTRODUCTION}

Anterior cervical discectomy and fusion (ACDF) is an established procedure for treatment of degenerative cervical disease. Anterior cervical plating and screw fixation devices reduce the risk of non-union and hardware failure after $\mathrm{ACDF}^{5,7,14)}$. To achieve successful anterior cervical plate and screw fixation, screws must have strong pull out strength. Many biomechanical studies have focused on this issue specifically. Chen IH reported that subcortically and bicortically purcha- sed screws showed comparable stability before cyclic loading. Cyclic loading deteriorated the construct-bone relationship in both groups, yet bicortically purchased screws rendered addi-

- Received: June 10, 2014 - Revised: August 2, 2014

- Accepted: August 20, 2014

Corresponding Author: Sung-Uk Kuh, MD, PhD

Department of Neurosurgery, Spine and Spinal Cord Institute, Yonsei University College of Medicine, 712, Eonjuro, Gangnam-gu, Seoul, Korea Tel: +82-2-2019-3404, Fax: +82-2-3461-9229

E-mail: kuhsu@yuhs.ac

®This is an Open Access article distributed under the terms of the Creative Commons Attribution Non-Commercial License (http://creativecommons.org/ licenses/by-nc/3.0/) which permits unrestricted non-commercial use, distribution, and reproduction in any medium, provided the original work is properly cited. tional stability in anterior cervical plating ${ }^{3,4,12)}$. Plates without locking screws require standard cortical screws and bicortical purchase is recommended ${ }^{1,2)}$. Current anterior cervical plate systems, however, are developed with locking fixation screws, which enhance fixation rigidity and pull out strength. This means that locking screws do not require penetration of the posterior vertebral cortex ${ }^{7,8,9,13)}$. Because pull out strength is directly correlated with the vertebrae body antero-posterior (A-P) diameter, longer subcortical screws are crucial for the ACDF procedure ${ }^{14)}$. However, deeper screw depth increases the risk of posterior cortical bone violation and can increase complications such as dural perforation, epidural hematoma, and spinal cord injury. Therefore, achieving the correct screw purchase depth without violating or penetrating the posterior cortical wall is critical. We recently developed a surgical method for this purpose. In this study, we compared our surgical method to a control group in a retrospective manner. We investigated the effectiveness of this surgical method for achieving proper screw purchase depth during ACDF procedures.

\section{MATERIALS AND METHODS}

We enrolled 81 adult patients who underwent ACDF using 
an anterior cervical plate at our hospital between 2010 and 2012. The patients had herniated cervical discs between levels one and three. Patients were categorized into Groups A (42 patients with retractor pins as a reference for screw length) and Group B (39 patients in the control group). Data were collected retrospectively by a single examiner using standardized data collection forms. Patient demographics indicated that there were no significant differences between the two groups (Table 1).

An intraoperative lateral x-ray was performed after the placement of one retractor pin to confirm the approaching vertebral level (Fig. 1). The distance between the tip of the retractor pin and the posterior cortical wall was measured as a reference to be used when deciding proper screw length for ACDF procedures. The purpose of this procedure was to select the longest length of screw possible for obtaining strong pull out strength without penetrating the posterior cortical wall. In Group B, level marking was performed by conventional methods such as disc space needling without retractor pinning. Retraction of each vertebrae was done with the vertebrae spreader. Screw length was determined by measuring the AP diameter in CT scan and the experience of the surgeon about the height, body weight and gender of the patient.

\section{RESULTS}

Because the actual length of threaded portion of the retractor pin is uniform $(16 \mathrm{~mm})$, the ratio of the retractor pin to A-P diameter could be used as a reference value. If the percentage of purchased depth was more than $90 \%$ compared to the A-P diameter or if it penetrated the posterior wall, we used 14-mm screws; this occurred in 10 cases. If the depth was less than $90 \%$, we used $16-\mathrm{mm}$ screws; this occurred in 32 patients within Group A. The average distance from screw tip to posterior wall was $3.0 \pm 1.4 \mathrm{~mm}$ in Group A and $4.1 \pm$ $2.3 \mathrm{~mm}$ in Group B. The ratio of screw length to body A-P diameter was $86.2 \pm 5.7 \%$ in Group A and $80.8 \pm 9.0 \%$ in Group B. The ratio of screw length to body A-P diameter over 4/5 was 33 (90\%) in Group A and 23 (59\%) in Group B (Table 2). Patients in Group A were statistically more likely

Table 1. Patient demographics

\begin{tabular}{lcll}
\hline \hline Patient factors & Group A & Group B & p-value \\
\hline Age & $53.3 \pm 10.5$ & $54.2 \pm 11.4$ & $0.509^{*}$ \\
Sex M:F & $27: 15$ & $24: 15$ & $0.798^{+}$ \\
Stature & $164.9 \pm 8.5$ & $163.4 \pm 7.2$ & $0.294^{*}$ \\
BMl & $24.4 \pm 2.6$ & $24.6 \pm 2.7$ & $0.984^{*}$ \\
\hline
\end{tabular}

${ }^{*}$ Student's t-test, ${ }^{+}$Chi-square test to have a higher ratio than Group B with an odds ratio of 6.6. There were no cases where the posterior cortical wall was violated in either group. There was only one case of disc space violation by a retractor pin in Group A(Fig. 2). Fortunately, the violated disc was the lesion to be taken diskectomy and fusion and hardware-related complications did not occur in this case.

\section{DISCUSSION}

Orozcor and Llovet first approved the use of anterior cervical plate stabilization for fixation of the traumatically unstable spine in $1970^{11)}$. The use of anterior cervical plating devices enhance spinal stability in ACDF procedures. These plates offer advantages such as improved fusion rate and lower risk of graft failure ${ }^{5)}$. Caspar et al. developed commercially available screw and plate fixation in 1989. This was an important addition to surgical treatment of cervical trauma. Caspar and Goffin emphasized the importance of penetration to the posterior vertebral body cortex for enhancing stability. Caspar reported a $5 \%$ incidence of screw pull out related to poor purchase in the posterior cortical bone of the vertebral body ${ }^{2}$. However, placement of such screws require care to assure that the posterior cortex is engaged but that the screws do
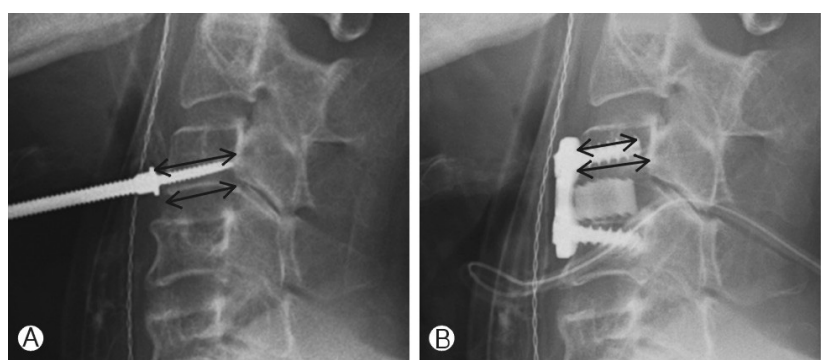

Fig. 1. A: Intraoperative x-ray film was taken after placing the retractor pin. In this example, the ratio of retractor pin to vertebrae A-P diameter was over $90 \%$, so a $14-\mathrm{mm}$ screw was used. B: Post operative film showed that the ratio of screw length to body A-P diameter was over $4 / 5$.

Table 2. Results

\begin{tabular}{lccc}
\hline \hline Patient factors & Group A & Group B & p-value \\
\hline $\begin{array}{l}\text { Distance from screw tip to } \\
\text { posterior wall (mm) }\end{array}$ & $3.0 \pm 1.4$ & $4.1 \pm 2.3$ & $0.008^{*}$ \\
$\begin{array}{l}\text { Screw length/ } \\
\text { Body A-P diameter (\%) }\end{array}$ & $86.2 \pm 5.7$ & $80.8 \pm 9.0$ & $0.011^{*}$ \\
$\begin{array}{l}\text { Screw length/Body sagittal } \\
\text { diameter >80\% }\end{array}$ & \\
\hline Odd's ratio & 6.60 \\
\hline
\end{tabular}




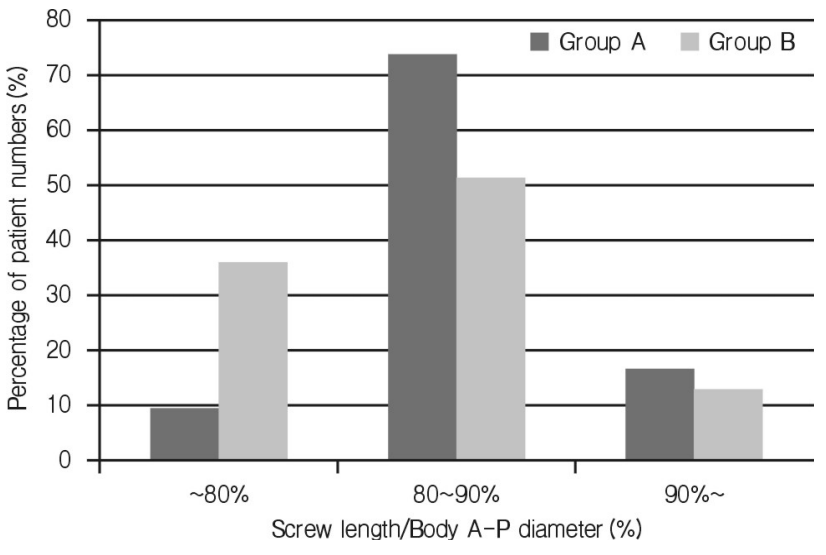

Fig. 2. The ratio of screw length to sagittal diameter.

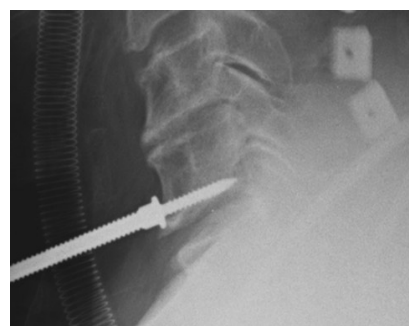

Fig. 3. A case in which disc space was violated by the retractor pin.

not enter too deeply into the spinal canal.

A new cervical spine locking plate (CSLP) system was developed that consisted of an $\mathrm{H}$-shaped plate anchored with a unicortical screw. The unicortical screw reduces risk of posterior wall penetration and provides sufficient pull out strength compared with a bicortical screw plating system ${ }^{4)}$.

There are multiple factors that influence the strength of anterior cervical screw and plate fixation. These factors include bone mineral density, bone geometry, plate and screw type, and screw length. The most important parameter of pull out strength, however, is screw length. Conrad et al. reported that $1 \mathrm{~mm}$ of increased screw length translates to $16 \mathrm{~N}$ of increased force of pull out in the foam bone model $^{6}$. For this reason, using the longest screw possible that does not penetrate the posterior cortical wall may be the best method for promoting strong pull out strength without risk of impingement on the spinal cord ${ }^{6,10)}$. In particular, strong pull out strength is required in osteoporotic patients because there needs to be enough ACDF strength for graft fusion.

To date, no literature has focused on surgical techniques of determining proper screw length in ACDF. Surgeons typically select screw length using parameters such as height, body weight, gender, and radiographs. This could result in uncertain or improper length choices. To address this problem, we describe an accurate surgical procedure that utilizes intraoperative radiographs to determine screw length. We employed an additional surgical method that utilizes the ratio of retra- ctor pin length to body A-P diameter as a reference value. Operative X-ray film results in altered magnification. This means that the distance is not completely accurate. Comparing the ratio of the vertebrae body's A-P diameter to the retractor pin length, which is $16-\mathrm{mm}$ in length, can mitigate this limitation. Another problem is that the screws have a cephalad angle of about 15 to 20 degrees. Actual screw purchase depth is somewhat shorter, about 10 to 14 percent shorter than the length of the screw. And the thickness of plate is also considered to effect the actual screw purchase depth. However, the shortening effect is no more than 2-mm in length and this difference should not affect the decision of screw length. In some cases, it is helpful to select $10 \%$ longer screw to get much deeper perchase depth.

There is risk of disc space violation at the adjacent level, but this risk can be overcome with meticulous measurements of disc angles during preoperative CT scans. Level needle localization can also be avoided with this method. As Ahmad et al. reported, incorrect needle localization is a relative risk for adjacent level disc degeneration ${ }^{10}$. Their study demonstrated that incorrectly marked disc levels have 3-fold increased degeneration. Our method of localizing the level by screwing only one retractor pin could avoid adjacent level degeneration caused by incorrect needling.

We show here that the ratio of screw length to body sagittal diameter was much higher in Group A. This means that a stronger pull out strength was obtained in Group A versus B. In summary, we used a retrospective group analysis that compared a surgical tool group with a control group. We were able to make a more accurate screw length decision in Group A, the surgical tool group.

\section{CONCLUSION}

Appropriate screw length and angles can be achieved using a retractor pin as a reference. This technique can decrease the risk of injury from mis-level disc needling. Intraoperative lateral x-ray is useful for anterior cervical screw and plate fixation in ACDF.

\section{DISCLOSURE}

The authors have no actual or potetinal conflict of interest in relation to this article.

\section{REFERENCES}

1. Bohler J, Gaudernak T: Anterior plate stabilization for fracturedislocations of the lower cervical spine. J Trauma 20(3):203-205, 
1980

2. Caspar W, Barbier DD, Klara PM: Anterior cervical fusion and caspar plate stabilization for cervical trauma. Neurosurgery 25(4): 491-502, 1989

3. Chen IH: Biomechanical evaluation of subcortical versus bicortical screw purchase in anterior cervical plating. Acta Neurochir (Wien) 138(2):167-173, 1996

4. Clausen JD, Ryken TC, Traynelis VC, Sawin PD, Dexter F, Goel VK: Biomechanical evaluation of caspar and cervical spine locking plate systems in a cadaveric model. J Neurosurg 84(6): 1039-1045, 1996

5. Connolly PJ, Esses SI, Kostuik JP: Anterior cervical fusion: Outcome analysis of patients fused with and without anterior cervical plates. J Spinal Disord 9(3):202-206, 1996

6. Conrad BP, Cordista AG, Horodyski M, Rechtine GR: Biomechanical evaluation of the pullout strength of cervical screws. J Spinal Disord Tech 18(6):506-510, 2005

7. Hui SW, Hee YK, Seok WK, Sung ML, Hyeun SK, Sung HK: Advantages of the plating for anterior cervical discectomy and fusion. Korean J Spine 8(3):161-164, 2011

8. Jonsson H, Jr., Cesarini K, Petren-Mallmin M, Rauschning W: Locking screw-plate fixation of cervical spine fractures with and without ancillary posterior plating. Arch Orthop Trauma Surg 111(1):1-12, 1991

9. Kostuik JP, Connolly PJ, Esses SI, Suh P: Anterior cervical plate fixation with the titanium hollow screw plate system. Spine (Phila Pa 1976) 18(10):1273-1278, 1993

10. Nassr A, Lee JY, Bashir RS, Rihn JA, Eck JC, Kang JD, et al: Does incorrect level needle localization during anterior cervical discectomy and fusion lead to accelerated disc degeneration? Spine (Phila Pa 1976) 34(2):189-192, 2009

11. R Orozco TL: Osteosintesis en las fractures de raquis cervical. Rev Ortop Traumatol 14:285-288, 1970

12. Ryken TC, Goel VK, Clausen JD, Traynelis VC: Assessment of unicortical and bicortical fixation in a quasistatic cadaveric model. Role of bone mineral density and screw torque. Spine (Phila Pa 1976) 20(17):1861-1867, 1995

13. Spivak JM, Chen D, Kummer FJ: The effect of locking fixation screws on the stability of anterior cervical plating. Spine (Phila Pa 1976) 24(4):334-338, 1999

14. Wang JC, McDonough PW, Endow KK, Delamarter RB: Increased fusion rates with cervical plating for two-level anterior cervical discectomy and fusion. Spine (Phila Pa 1976) 25(1): 41-45, 2000 